\title{
Prevalence of ESBL-mediated Resistance among Hospital and Community isolates of Klebsiella pneumoniae in Warangal
}

\author{
Usha Vidya Rani $S^{1}$, Ramanamma $\mathrm{MV}^{2}$,Mukherjee $\mathrm{AL}^{3}$, Suneesh Jacob $\mathrm{A}^{4}$ \\ ${ }^{1}$ Dr. Shodavaram Usha Vidya Rani, Assistant Professor, Department of Microbiology, S.V. Medical College, Tirupati, \\ Andhra Pradesh, India, ${ }^{2}$ Dr. Mallajosyula Venkata Ramanamma, Director of Medical Education (Retd.), Government of \\ Andhra Pradesh, Hyderabad, Andhra Pradesh, India, ${ }^{3}$ Dr. Arava Lazarus Mukherjee, Assistant Professor, Department of \\ Orthopedics, ACSR Govt. Medical College, SPSR Nellore, Andhra Pradesh, India. ${ }^{4}$ Dr. Akkarapakam Suneesh Jacob, \\ Research Scholar, Indian Institute of Technology, Kanpur, Uttar Pradesh, India.
}

Address for correspondence: Dr. Shodavaram Usha Vidya Rani,E-mail: ushavidyarani@ yahoo.co.in

\begin{abstract}
Introduction: Extended Spectrum $\beta$-Lactamase (ESBL) producing Klebsiella pneumoniae were prevalent in the hospital environment and were responsible for many hospital associated infections (HAIs). The present study was aimed at identifying these strains in the hospital environment so as to guide the clinician in planning antibiotic policy. Material and Methods: 200 clinical isolates of Klebsiella pneumoniae constituted the study group. 100 isolates were from the community and 100 from the hospital. Based on their susceptibility or resistance to $3^{\text {rd }}$ generation cephalosporins (3GCs), the isolates were characterized into two groups. Group I consisted of sensitive strains (128 numbers) which showed a zone diameter of more than $17 \mathrm{~mm}$ and group II consisted of resistant strains ( 72 numbers) which showed a zone diameter of less than $17 \mathrm{~mm}$ to ceftazidime $(30 \mu \mathrm{g})$, cefotaxime $(30 \mu \mathrm{g})$ and ceftriaxone $(30 \mu \mathrm{g})$. Isolates of group II were tested for ESBL production using two methods namely double disc synergy test (DDST) and phenotypic confirmatory disc diffusion test (PCDDT). Results: Among the 72 resistant strains, $36(50 \%)$ were ESBL producers and $36(50 \%)$ were non-ESBL producers. Among the hospital isolates, the percentage of ESBL producers was more (30\%) compared to the community isolates $(6 \%)$. Conclusion: About one third of the hospital isolates of Klebsiella pneumoniae showed ESBL production whereas ESBL mediated resistance was low in community isolates. This study substantiated the need for planning proper antibiotic policy to reduce mortality due to Gram-negative sepsis.
\end{abstract}

Keywords: Extended spectrum beta lactamases (ESBLs), Double disc synergy test (DDST), Hospital associated infections (HAIs), Phenotypic confirmatory disc diffusion test (PCDDT) and Third generation cephalosporins (3GCs).

\section{Introduction}

Klebsiella pneumoniae is one of the commonest organisms causing sepsis in the hospital as well as in the community. Colonization in the oropharynx especially of hospitalized patients may be the source of lung infections indebilitated patients [1]. Nosocomial outbreaks due to multi-drug resistant Klebsiella pneumoniae are also reported [2]. ESBLs are more prevalent in Klebsiella pneumoniae than any other Enterobacteriaceae species and are often undetected by routine susceptibility testing methods where only one disc of any one of the 3GCs is used. Occurrence of ESBL producing Klebsiella pneumoniae has been

Manuscript received $27^{\text {th }}$ April 2016

Reviewed: $14^{\text {th }}$ May 2016

Author Corrected: $24^{\text {th }}$ May 2016

Accepted for Publication $11^{\text {th }}$ June 2016 reported in India [3]. As no documented information is available with regard to the extent of spread of the ESBL producing strains of Klebsiella pneumoniae in the hospital and community in Warangal region an attempt was made to identify ESBL producing Klebsiella pneumoniae among hospital and community isolates using two different techniques namely double disc synergy test (DDST) [4] and phenotypic confirmatory disc diffusion test (PCDDT) [5, 6].

\section{Material and Methods}

Two hundred clinical isolates of Klebsiella pneumoniae isolated from various clinical samples of both outpatients and in-patients constituted the study material. 
One hundred isolates were from the out-patients and a hundred from in-patients. Institution ethical committee approval has been obtained. Identification of the strains was done as per the standard guidelines [1] (Figures1 and2). Antibiogram of the isolates was studied with a set of eight antibiotic discs consisting of amoxycillin $(30 \mu \mathrm{g})$, gentamycin $(10 \mu \mathrm{g})$, amikacin $(30 \mu \mathrm{g})$, ciproflixacin $(30 \mu \mathrm{g})$, cefuroxime $(30 \mu \mathrm{g})$, ceftazidime $(30 \mu \mathrm{g})$, cefotaxime $(30 \mu \mathrm{g})$ and ceftriaxone $(30 \mu \mathrm{g})$. The isolates were categorized into two groups based on their susceptibility or resistance to 3GCs. Group I consisted of sensitive strains which had shown a zone diameter of more than $17 \mathrm{~mm}$ for all the 3GCs. Group II were resistant strains, which had shown a zone diameter of less than $17 \mathrm{~mm}$ for any one of the 3GCs [7]. Strains belonging to the second group were tested for ESBL production by 2 methods namely DDST and PCDDT.

Double disc synergy test (DDST) was done using amoxycillin $20 \mu \mathrm{g}$ and clavulanic acid $10 \mu \mathrm{g}$ (augmentin), and discs of 3GCs (ceftazidime, ceftriaxone and cefotaxime). The test inoculum ( 0.5 McFarland's turbidity) was spread onto MuellerHinton agar (MHA) by using a sterile cotton swab. A disc of augmentin $(20 \mu \mathrm{g}$ amoxicillin $+10 \mu \mathrm{g}$ clavulanate $)$ was placed on the surface of the MHA, then discs of cefotaxime $(30 \mu \mathrm{g})$, ceftaziime $(30 \mu \mathrm{g})$ and ceftriaxone $(30 \mu \mathrm{g})$ were kept $16-20 \mathrm{~mm}$ apart from augmentin disc (center to center). The plates were incubated at $37^{\circ} \mathrm{C}$ overnight. The enhancement of the zone of inhibition of the cephalosporin disc towards the clavulanic acid disc was inferred as synergy and the strain was considered as an ESBL producer [4] (Figure 3).

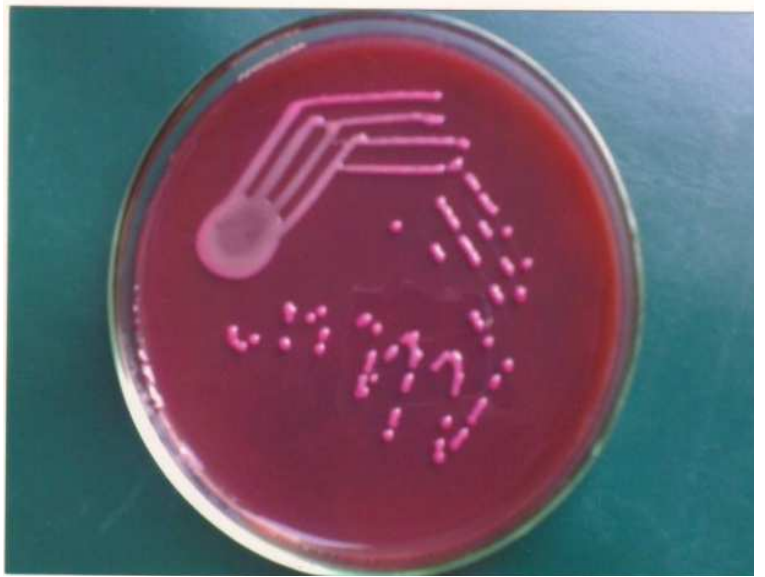

Fig. 1: Lactose fermenting mucoid colonies of Klebsiella pneumoniae on MacConkey's gar

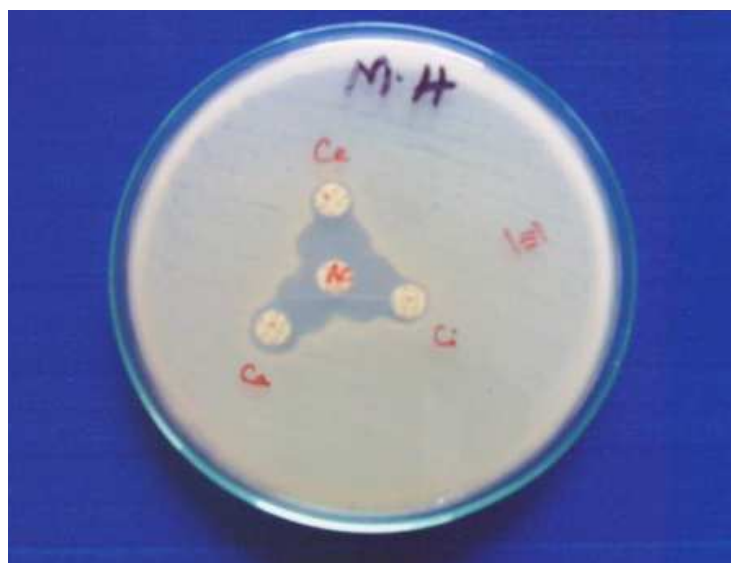

Fig 3: ESBL production detected by DDST

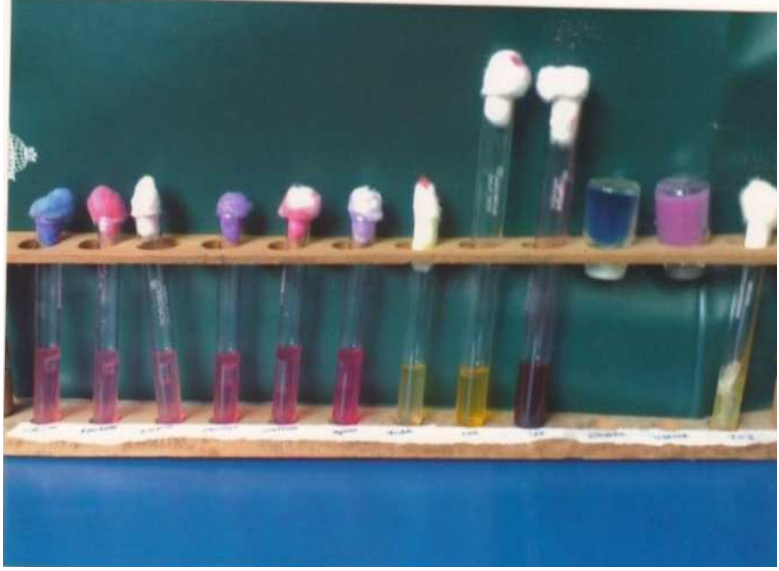

Fig 2: Biochemical reactions of Klebsiella pneumoniae

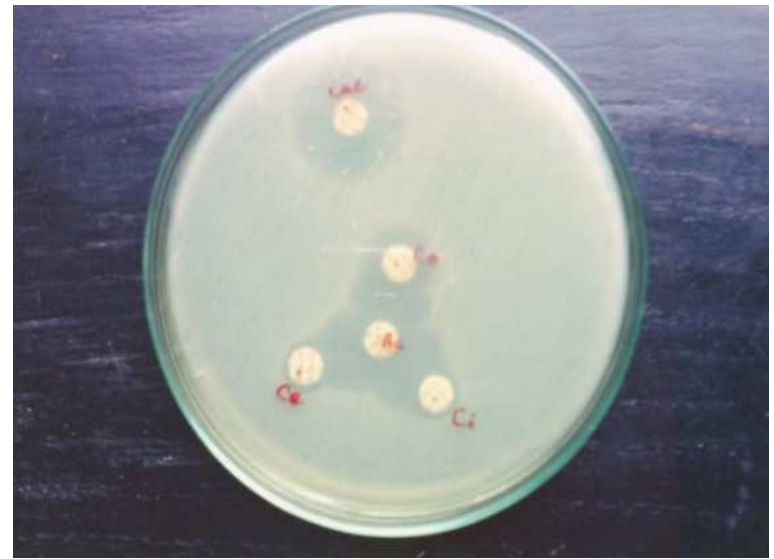

Fig 4: ESBL detected by DDST \& PCDDT on same plate

Phenotypic confirmatory disc diffusion test (PCDDT) was performed as a disc diffusion test as recommended by the CLSI. The test inoculum (0.5 McFarland's turbidity) was spread onto the MHA by using a sterile cotton swab and then a ceftazidime $(\mathrm{Ca})$ disc containing $30 \mu \mathrm{g}$ of the antibiotic and ceftazidime + clavulanic acid $(\mathrm{CaC})$ disc containing 20 
$\mu \mathrm{g}+10 \mu \mathrm{g}$ of the antibiotics respectively were placed at a distance of $30 \mathrm{~mm}$ from each other. The plates were incubated overnight at $37^{\circ} \mathrm{C}$ and the results were read. A $>5 \mathrm{~mm}$ increase in the zone diameter for CaC versus its zone diameter when it was tested alone by Ca confirmed an ESBL producing organism. All the discs were obtained from Hi-Media, India. In PCDDT, an increase of zone diameter more than $5 \mathrm{~mm}$ around a ceftazidime+clavulanic acid disc when compared to ceftazidime disc alone was considered as ESBL producer [5, 6] (Figure 4). The control strains used in the present study were Klebsiella pneumoniae ATCC 700603 (as positive control), Escherichia coli ATCC 25922 (as negative control) and in-house control.

\section{Results}

The overall prevalence rate of 3GC-resistant Klebsiella pneumoniae was 36\% (Hospital and Community isolates together). Among the two hundred isolates of the test group, 72were resistant to the 3GCs (zone diameter of less than $17 \mathrm{~mm})$. (TABLE I). The prevalence of $3 \mathrm{GC}$ resistance was more in the hospital $(60 \%)$ compared to the community isolates (12\%). Among the $3 \mathrm{GC}$ resistant hospital isolates $50 \%$ were ESBL producers. (TABLE II). The maximum percentage (26\%) of ESBL producing strains was from pus samples. (TABLE III).

Table I: Sensitivity and resistance patterns of Klebsiella pneumoniae isolates to 3GCs.

\begin{tabular}{|c|c|c|c|c|}
\hline \multirow{2}{*}{$\begin{array}{c}\text { Total No. of } \\
\text { isolates }\end{array}$} & \multicolumn{2}{|c|}{ Sensitive to 3GCs } & \multicolumn{2}{c|}{ Resistant to 3GCs } \\
\cline { 2 - 5 } & No. & Percentage & No. & Percentage \\
\hline 200 & 128 & $64 \%$ & 72 & $36 \%$ \\
\hline
\end{tabular}

Table II: Distribution of Klebsiella pneumoniae isolates based on ESBL production.

\begin{tabular}{|c|c|c|c|c|c|c|c|}
\hline \multirow{3}{*}{ Group } & \multirow{3}{*}{$\begin{array}{l}\text { Total no. } \\
\text { of isolates }\end{array}$} & \multirow{2}{*}{\multicolumn{2}{|c|}{ Sensitive to 3GCs }} & \multicolumn{4}{|c|}{ Resistant to 3GCs } \\
\hline & & & & \multicolumn{2}{|c|}{ ESBL producers } & \multicolumn{2}{|c|}{ Non ESBL producers } \\
\hline & & No. & Percentage & No. & Percentage & No. & Percentage \\
\hline Hospital & 100 & 40 & $40 \%$ & 30 & $30 \%$ & 30 & $30 \%$ \\
\hline Community & 100 & 88 & $88 \%$ & 6 & $6 \%$ & 6 & $6 \%$ \\
\hline Total & 200 & 128 & $64 \%$ & 36 & $18 \%$ & 36 & $18 \%$ \\
\hline
\end{tabular}

Table III: Sample-wise distribution of ESBL producing Klebsiella pneumonia.

\begin{tabular}{|c|c|c|c|}
\hline \multirow[t]{2}{*}{ Samples } & \multirow{2}{*}{$\begin{array}{c}\text { No. of Klebsiella pneumoniae } \\
\text { isolates }\end{array}$} & \multicolumn{2}{|c|}{ ESBL producing Klebsiella pneumoniae isolates } \\
\hline & & No. & Percentage \\
\hline Pus & 46 & 12 & $26.08 \%$ \\
\hline Sputum & 106 & 12 & $11.32 \%$ \\
\hline Urine & 42 & 8 & $19.04 \%$ \\
\hline Stool & 4 & 2 & $50.00 \%$ \\
\hline Blood & 2 & 2 & $100.00 \%$ \\
\hline
\end{tabular}

Table IV: Percentage of ESBL in different study groups in India

\begin{tabular}{|c|l|l|c|c|c|}
\hline S. No. & \multicolumn{1}{|c|}{ Place } & \multicolumn{1}{|c|}{ Author } & No. studied & No. of ESBL producers & Percentage \\
\hline 1 & Delhi & Revathi [9] & 100 & 53 & $53.00 \%$ \\
\hline 2 & Chennai & Subha and Ananthan [10] & 120 & 8 & $6.66 \%$ \\
\hline 3 & Aligarh, U. P. & Shukla et al [11] & 120 & 32 (by PCDDT) & $26.66 \%$ \\
& & & & 29 (by DDST) & $24.16 \%$ \\
\hline 4 & Haryana & Singhal et al [12] & 272 & 173 & $63.60 \%$ \\
\hline 5 & Chennai & Menon et al [13] & 70 & 14 & $20.00 \%$ \\
\hline 6 & Warangal, A. P. & Usha et al & 200 & 72 & $36.00 \%$ \\
\hline
\end{tabular}




\section{Discussion}

The predilection of ESBLs for Klebsiella pneumoniae in the hospital environment is probably due to their longer survival in the hospital thus facilitating cross infection [6]. In the hospital, the environmental sources of ESBL producing organisms are ultrasonography coupling gel, bronchoscopes, blood pressure cuffs, glass thermometers to name a few. Sink basins and babies' baths have also been discovered to have been contaminated [8]. The present study was the first attempt to know the percentage of $3 \mathrm{GC}$ resistant Klebsiella pneumoniae isolates in Warangal.

Revathi from Delhi tested 100 clinical isolates of Gramnegative bacilli for production of ESBLs with the E-test ESBL strip. 53 isolates were ESBL positive [9]. Subha and Ananthan from Chennai studied a total of 120 isolates of Klebsiella pneumoniae. $87 \%$ of the isolates showed resistance to all the 3GC antibiotics. ESBL production was detected in 8 strains. The ESBL activity could experimentally be transferred to recipient Escherichia coli K12 J62-2 [10]. Shukla et al from Aligarh, Utter Pradesh, India tested 120 multi-drug resistant strains of Klebsiella pneumoniae. The strains were studied for ESBL production by PCDDT and DDST. $72 \%$ of the isolates were resistant to all the 3GCs. 32 strains showed ESBL production by PCDDT and 29 by DDST. Resistance was transferred to recipient Escherichia coli K12 J-62-1 [11]. Singhal et al from Haryana screened 272 isolates for ESBL and AmpC $\beta$-lactamase by modified double disc approximation method. 173 of the isolates $(64 \%)$ were found to be ESBL positive [12].

Menon et al studied ESBL production among members of Enterobacteriaceae in a tertiary care center in Chennai. The methods used were DDST and three dimensional tests. Among 70 strains, $20 \%$ were ESBL producers. Three dimensional test was found to be better than DDST. In DDST method a distance of 15 mm was maintained between $3 \mathrm{GC}$ and Augmentin [13].

In our present study of 200 isolates $72(36 \%)$ were found to be ESBL producers. The range of percentages was from 6 to 64\%. (TABLEIV). This is understandable as the prevalence of ESBL producers of any hospital depends upon various factors like the hospital antibiotic policy, the carriage rate of the organism in the hospital environment and the type of disinfectants practiced in the hospitals especially in the intensive care units. These strains are often undetected because of the usage of only one antibiotic disc belonging to 3GCs. Strains showing significant zones of inhibition often pass off as sensitive while in reality they are resistant often with ESBL production. Thus it is mandatory to include a minimum of any three of the antibiotics of 3GCs. Strains resistant to any one of the three $3 \mathrm{GCs}$ are to be taken as resistant and should be tested for ESBL production. Gastrointestinal colonization among hospitalized patients is a significant risk factor for spreading ESBL resistance in the hospital environment [14].

The observations in the present study indicate the possible methods of clinical approach as detailed below to reduce mortality and morbidity due to ESBL producing hospital strains of Klebsiella pneumoniae: avoid injudicious use of 3GCs without assessing the sensitivity pattern of the clinical isolate, formulate a policy of empirical therapy in high risk units [15] and devise protocols to reduce the prevalence of drug resistant bacteria in the hospital environment. In short, the prevention and management of infections caused by ESBL producing organisms requires a well coordinating activity of the microbiologist, the clinician, the hospital paramedics and the hospital infection control team.

\section{Conclusions}

Among 200 clinical isolates studied, 72 (36\%) strains were resistant to 3GCs. Out of them 60 were from hospital environment and 12 were community isolates. ESBL producers were more in the hospital isolates (30\%) compared to the community isolates (6\%). Most of the ESBL producing Klebsiella pneumoniae isolates were from pus samples. To get an accurate picture of resistance to $3 \mathrm{GCs}$, the isolate has to be tested for susceptibility to at least three of the 3GCS.

Acknowledgements: Authors are grateful to Dr. B. Appala Raju, Professor and Head of the Department of Microbiology, PSG Institute of Medical Science and Research, Coimbatore for extending help to procure material for the present study and thankful to Dr. I. L. Ramesh, our well-wisher for all his moral support and encouragement towards the study and last but not the least, Dr. Hari Krishna, Asst. Professor of Physiology for extending help in computer and online techniques.

Funding: Nil, Conflict of interest: None initiated. Permission from IRB: Yes 


\section{References}

1.Koneman EW, Allen SD, Janda WM, Schreekenberger PC, Winn WC Eds. Enterobacteriaceae, Antimicrobial Susceptibility Testing. In: Color Atlas and Text Book of Diagnostic Microbiology. $5^{\text {th }}$ Edition, 1997. J. B. Lippincott Company, Philadelphia, New York. 207, 779-798,831.

2. Mahon CR and Manuselis, Jr. Enterobacteriaceae In: Text book of Diagnostic Microbiology, 1995. W. B. Saunders Company, a Division of Harcourt Brace \& company. Philadelphia London Toronto Montreal Sydney Tokyo. 456-457.

3. Subha A, Ananthan S. Extended spectrum beta lactamase (ESBL) mediated resistance to third generation cephalosporins among Klebsiella pneumoniae in Chennai. Indian Journal of Medical Microbiology, (2002) 20(2):92-95.

4.Jarlier V, Nicolas M, Foumier G, Philippon A. Extended spectrum $\beta$-lactamases conferring transferable resistance to newer $\beta$-lactam agents in Enterobacteriaceae: Hospital prevalence and susceptibility patterns. Rev Infect Dis 1988; 867-78.

5.Clinical Laboratory Standards: Performance standards for antimicrobial susceptibility testing;Eighth informational supplement. M100-S8. NCCLS, Wayne, PA: 1998; 7767 Clinical and Laboratory Standards Institute. 2005 guidelines by CSLI/NCCLS-CSLI informational supplement. Approved standard M100S15 Wayne, PA; 200;565.

6. Paterson DL and Bonomo RA. Extended-spectrum $\beta$ lactamases: a Clinical Update. Clinical, Microbiology Reviews. Oct. 2005.p. 657-686.

7.National Committee for Clinical Laboratory standards: performance Standards for antimicrobial susceptibility test, $5^{\text {th }}$ ed. (Villanova, PA: NCCLS) 1993: DOCUMENT M2 - A5.
8. Eisen, D., E. G. Rusell, M. Tymms, E., J. Rper, M. L., Grayson, and J. Turnidge, 1995, Randomamplified polymorphic DNA.

9. Revathi G, Singh S. Detection of Expanded spectrum cephalosporin Resistance due to inducible $\beta$-lactamases in hospital isolates. Indian J Med Microbiol 1997; 15 (3):113-115.

10. Subha A, Ananthan S. Extended spectrum beta lactamase (ESBL) mediated resistance to thirdgeneration cephalosporins among Klebsiella pneumoniae in Chennai. Indian Journal of Medical Microbiology, (2002) 20(2):92-95.

11. Shukla I, Tiwari R, Agarwal M. Prevalence of Extended Spectrum $\beta$-lactamase Producing Klebsiellapneumoniae in a Tertiary Care Hospital, Indian Journal of Medical Microbiology.(2004)(2):87-91.

12. Singhal S, Mathur T, Khan S, Upadhyay DJ, Chug $\mathrm{S}$, Giand R, Rattan A. Evaluation of methods forAmpC $\beta$-lactamase in Gram-negative clinical isolates from tertiary care hospitals. IndianJournal of Medical Microbiology, (2005) 23 (2): 120-124.

13. Menon $\mathrm{T}$, Bindu $\mathrm{D}$, Kumar $\mathrm{CPG}$, Nalini $\mathrm{S}$, Thiruvarayan MA. Comparison of Double Disc andThree Dimensional Methods to screen for ESBL producers in a Tertiary Care Hospital. Indian Journal of Medical Microbiology. (2006) 24 (2): 117-120.

14. Lucet JC, Decre D, Fichelle A, Joly-Guillou ML, Pernet M, Deblangye, et al. Control of a prolonged outbreak of Extended spectrum $\beta$-lactamase producing Enterobacteriaceae in a University Hospital. Clin Infect Dis 1999; 29:1411-8.

15. Mathur P, Kapil A, Das B, Dhawan B. Prevalance of ESBL Producing Gram-negative bacteria in a tertiary care hospital. Indian J Medical Res 2002; 115:153-157.

\section{How to cite this article?}

Usha Vidya Rani S, Ramanamma MV, Mukherjee AL, Suneesh Jacob A. Prevalence of ESBL-mediated Resistance among Hospital and Community isolates of Klebsiella pneumoniae in Warangal. Int J Med Res Rev 2016;4 (6):10051009.doi: 10.17511/ijmrr.2016.i06.24. 